Longitudinal study

\section{Professional socialisation processes help facilitate the transition from student to qualified nurse}

10.1136/ebnurs-2019-103078

Úna Kerin

Adult Nursing, Birmingham City University, Birmingham, UK

Correspondence to: Úna Kerin, Adult Nursing, Birmingham City University, Birmingham B15 3TN, UK; una.kerin@bcu.ac.uk

Commentary on: Frögéli E, Rudman A, Gustavsson P. The relationship between task mastery, role clarity, social acceptance, and stress: an intensive longitudinal study with a sample of newly registered nurses. Int J Nurs Stud 2019;91:60-9. doi: 10.1016/j. ijnurstu.2018.10.007

\section{Implications}

- Socialisation processes are needed to enhance role transition and improve the integration of newly qualified nurses (NQNs). A particular emphasis should be placed on fostering social acceptance.

- This study provides a theoretical basis on which an intervention could be generated to minimise NQN stress.

- Future studies investigating stress in NQN should also consider the influence of organisational work factors including staffing levels, skill-mix and workload allocations.

\section{Context}

The transition from student to newly qualified nurse (NQN) is a vulnerable time period. ${ }^{12}$ The challenges of increased clinical responsibility and settling into the clinical work environment can increase stress levels and cause some graduate nurses to consider leaving the profession. ${ }^{3}$ Attrition rates are reportedly high during the initial 3 years' postqualification. ${ }^{4}$ High attrition rates are especially concerning when one considers the current global nursing shortage. Frögéli and colleagues ${ }^{5}$ investigate the relationship between professional socialisation processes and stress in NQNs. Increased understanding of stress antecedents will enable healthcare leaders to develop targeted interventions, which can improve graduate nurse's transition.

\section{Methods}

Frögéli and colleagues ${ }^{5}$ prospective longitudinal study recruited NQNs following summer 2015 and spring 2016 graduations in Sweden. Participants represented all Swedish healthcare regions. Baseline demographics were collated using an online survey and the study's sample size was decided using a power calculation. Data collection occurred during the first 13 weeks' postqualification. Validated surveys evaluating 'stress', 'task mastery', 'role clarity' and 'social acceptance' were sent to participants online and data were gathered every other week. Researchers adopted Bolger and Laurenceau's ${ }^{6}$ longitudinal data analysis methods.

\section{Findings}

During the first 13 weeks as a qualified nurse, there was a trend towards a progressive increase in role clarity and task mastery, and a decrease in stress. ${ }^{5}$ Decreased social acceptance was also reported. ${ }^{5}$ While these trends highlight the average NQN transitionary response, some nurses progressed more or less effectively than average. These findings illustrate a potential link between organisational social support and NQN stress, with stress levels reportedly lower in nurses who received increased social support.

\section{Commentary}

Professional socialisation and the 'fitting-in' process is a source of stress for some NQNs and it has been suggested that NQNs find the process of developing professional identity, role clarity, skill mastery and social acceptance challenging. ${ }^{5}$ Frögéli and colleagues ${ }^{5}$ longitudinal study illustrated a trend towards a progressive increase in role clarity and task mastery, and a decrease in stress. Other findings reveal an apparent decrease in social acceptance. The latter findings will concern healthcare managers as NQNs are at high risk of making clinical errors in the initial months' postqualification and collegial support is necessary to improve patient safety. ${ }^{3}$ Additionally, poor coworker relations are associated with job dissatisfaction which can contribute to nurse burnout. ${ }^{2}$ Cumulatively, these findings highlight the need for NQN socialisation processes that enhance role transition and improve integration into the complex clinical working environment. Findings from Frögéli and colleagues ${ }^{5}$ also provide a theoretical basis on which an intervention could be generated to minimise NQN stress. Future studies investigating stress in NQN should also consider the important influence of organisational work factors including staffing levels, skill-mix and workload allocations. ${ }^{2}$

Competing interests None declared.

Provenance and peer review Commissioned; internally peer reviewed.

๑ Author(s) (or their employer(s)) 2020. No commercial re-use. See rights and permissions. Published by BMJ.

\section{Check for updates}

ORCID iD

Úna Kerin http://orcid.org/0000-0003-0709-1112

\section{References}

1. Hunter K, Cook C. Role-modelling and the hidden curriculum: New graduate nurses' professional socialisation. J Clin Nurs 2018;27(15-16):3157-70.

2. Spence Laschinger HK, Wong C, Read E, et al. Predictors of new graduate nurses' health over the first 4 years of practice. Nurs Open 2019;66:245-59.

3. Gardiner I, Sheen J. Graduate nurse experiences of support: A review. Nurse Educ Today 2016;40:7-12.

4. Kovner CT, Brewer CS, Fatehi F, et al. What does nurse turnover rate mean and what is the rate? Policy Polit Nurs Pract 2014;15(3-4):64-71.

5. Frögéli E, Rudman A, Gustavsson P. The relationship between task mastery, role clarity, social acceptance, and stress: An intensive longitudinal study with a sample of newly registered nurses. Int J Nurs Stud 2019;91:60-9.

6. Bolger N, Laurenceau JP. Intensive longitudinal methods: An introduction to diary and experience sampling research. New York: Guilford Press, 2013. 